\title{
CRÉDITOS DE CARBONO E GERAÇÃO DE ENERGIA COM USO DE BIODIGESTORES NO TRATAMENTO DE DEJETOS SUÍNOS
}

\author{
Carbon Credits and Energy Generation with Use of the Bio- \\ digesters in the Treatment of Swine Manure
}

\author{
Tobias Carvalbo \\ Marcelo Antunes Nolasco ${ }^{2}$
}

\section{Resumo}

No presente trabalho, avaliou-se a viabilidade do uso de biodigestores para tratamento de dejetos suínos, visando seu enquadramento no modelo de Mecanismos de Desenvolvimento Limpo (MDL) previsto no Protocolo de Quioto e a obtenção de créditos de carbono e geração de energia. O projeto propõe a utilização de um Sistema para Manejo de Dejeto Animal (SMDA) de baixa emissão de Gases do Efeito Estufa (GEE), com o uso de um biodigestor anaeróbio, a temperatura ambiente para digestão dos dejetos e captura dos GEE emitidos desta, com posterior combustão do biogás resultante. Para elaboração da planilha de custos, foram considerados os de implantação e manutenção de uma unidade de biodigestão, o custo de validação, registro e verificação do projeto. Como benefícios do projeto foram considerados o ganho de capital com as vendas dos Certificados de Emissão de Redução (CERs) e o valor economizado com a geração de energia pelo combustão do biogás.

Palavras-chave: Protocolo de Quioto; Efeito estufa; Biogás; Biomassa; Biodigestores.

\section{Abstract}

In the present work it was evaluated the viability of the use of bio-digesters for treatment of swine dejections, aiming at its framing of the model of Clean Development Mechanism (CDM) foreseen in the Kyoto Protocol, aiming at the attainment of carbon credits and energy generation. The project considers the use of an Animal Manure Management System (AMMS) of low Greenhouse Gas Emission (GGE), with the use of an anaerobic digestion, at ambient temperature for the digestion of the manure and therefore with the capture of GGE, with subsequent combustion of biogas produced. For the costs evaluation, it was considered the implantation and maintenance of a unit of bio-digestion, the validation cost, registers and verification of the project. As benefits of the project it had been considered, the capital profit with sale of the Reduction Emission Certificates (RECs) and the value saved with the energy generation of through the combustion of biogas.

Keywords: Kyoto protocol; Greenhouse effect; Biogas; Biomass; Biodigesters.

1 Estudante de Agronomia. Centro de Ciências Agrárias e Ambientais da Pontifícia Universidade Católica do Paraná, BR 376, km 14. CEP 83.010-500, São José dos Pinhais-PR. E-mail: carvalhoeco@gmail.com.

2 Biólogo, Dr. Professor do Titular dos Cursos de Agronomia e Medicina Veterinária, Centro de Ciências Agrárias e Ambientais da Pontifícia Universidade Católica do Paraná, Câmpus São José dos Pinhais-PR. E-mail: marcelo.nolasco@pucpr.br. 


\section{Introdução}

A suinocultura se caracteriza pela criação de forma intensiva de suínos, o que gera uma quantidade grande de dejetos, que apresentam elevado potencial poluidor, tanto de águas quanto de solos. O uso de biodigestores é uma alternativa para o tratamento desses dejetos, reduzindo o nível de poluição.

A partir da década de 80, estudos constataram um aumento na temperatura média do planeta Terra. Em virtude disso, surge uma crescente preocupação sobre o fator do aquecimento global, fazendo com que a Organização das Nações Unidas para o Meio Ambiente e a Organização Meteorológica Mundial criassem o IPCC (Painel Intergovernamental sobre Mudanças Climáticas). Baseando-se nas conclusões do IPCC foi criado a Framework Convention on Climate Changes (Convenção Quadro das Nações Unidas sobre a Mudança do Clima), um documento que foi assinado por 175 países durante a Rio 92. A partir da realização dessa convenção, os países signatários passaram a reunir-se periodicamente para debaterem assuntos relacionados ao aumento da temperatura no planeta (KHALILI, 2005).

A partir dessas reuniões, concluiu-se que o principal causador das mudanças climáticas pelo qual passa o planeta é o aumento da concentração de gases que provocam o efeito estufa. Baseandose nesses estudos, a Conferência das Partes da ONU chegou à proposta do Protocolo de Quioto. É nesse Protocolo que os países em desenvolvimento e os que preservam, ao menos relativamente, os seus recursos naturais, não têm a necessidade de reduzir suas taxas de emissão de gases nocivos à camada de ozônio. Assim, podem passar a se estruturar para desenvolverem projetos visando a sustentabilidade social e ambiental, isso porque a essência do protocolo determina que quem polui deve assumir financeiramente as conseqüências (KHALILI, 2005).

Desta forma, o Brasil se torna um potencial gerador de projetos, dentro de dois segmentos previstos no Protocolo de Quioto, o Setor de Seqüestro de Carbono, com projetos de florestamento e reflorestamento, e o de Mecanismos de Desenvolvimento Limpo, sendo este a busca de alternativas de tecnologia menos poluidoras, como, por exemplo, a queima do gás metano $\left(\mathrm{CH}_{4}\right)$, gerando dióxido de carbono $\left(\mathrm{CO}_{2}\right)$. O que ocorre nesse processo é que $\mathrm{O}_{\mathrm{CH}}$ tem potencial poluidor referente ao GWP (Global Warming Potencial) 21 , enquanto que $\mathrm{O} \mathrm{CO}_{2}$ tem potencial poluidor GWP 1, assim a queima de gás $\mathrm{CH}_{4}$ reduz seu potencial de poluição em 20 vezes. Desta forma, atende aos critérios de adicionalidade, nos quais se diz que projetos de Mecanismos de Desenvolvimento Limpo deverão oferecer benefícios a longo prazo, reais e mensuráveis para os propósitos de mitigação da mudança do clima e redução do efeito estufa e promover uma redução de emissão que seja adicional, ou seja, uma redução de emissões que não seria obtida no caso da inexistência do projeto. Traça-se de uma linha de base (Baseline) na qual é determinado um cenário, demonstrando o que aconteceria se a atividade do projeto não ocorresse. A partir da linha de base, pode-se determinar a adicionalidade, que é basicamente o detalhamento das atividades do projeto (CEBDS, 2006).

No Japão, os custos de abatimento das emissões de Gases do Efeito Estufa podem chegar a US\$ 584,00/tonelada de carbono, enquanto que nos EUA atingiriam US\$ 186,00/tonelada de carbono e na Comunidade Européia US\$273,00/tonelada de carbono. Isso pode fazer com que projetos de abatimento em outros países se tornem mais interessantes, ou seja, menos onerosos (ROCHA, 2003).

Uma vez que existem diferentes custos de abatimento de Gases do Efeito Estufa, existem incentivos econômicos para que empresas comecem a oferecer esse tipo de serviço, denominado Comércio de Emissões ("emissions trade"). Criase, portanto, um valor de mercado para o carbono. O Banco Mundial, citado no Banco Nacional de Desenvolvimento Econômico e Social (BNDES), e o Ministério de Ciência e Tecnologia (MCT) (1999) estimam que o valor dos Certificados de Redução de Emissão de Gases do Efeito Estufa estará entre US\$ 5,00 e US\$ 15,00/tonelada de carbono reduzida (ROCHA, 2003).

O mercado mundial de troca de créditos de carbono com base em projetos de Mecanismo de Desenvolvimento Limpo saltou de US\$330 milhões em 2004 para US\$ 4 bilhões em 2005. Em termos práticos, o mercado de transações de Créditos de Carbono está começando agora, segundo o gerente de mudanças climáticas do banco ABN Amro Real (LOMBARDI, 2006).

Assim cria-se o mercado de carbono e a principal razão para sua criação decorre das dife- 
renças de custos de redução das emissões de Gases do Efeito Estufa em projetos de mitigação, como os previstos nos Mecanismos de Desenvolvimento Limpo, e o custo para se alcançar essa mesma redução em uma grande unidade produtiva, ou seja, torna-se mais viável (barato) para os países do Anexo I (leia-se países desenvolvidos) investirem na compra de Certificados de Emissões de Redução do que reduzirem suas próprias emissões. Qualquer segmento produtivo que almeje reduzir as emissões de Gases do Efeito Estufa a longo prazo terá que se dispor a executar grandes alterações nas plantas de produção para que as metas de reduções sejam alcançadas. Isso ocasiona um custo maior por tonelada reduzida no seu projeto do que aquele pago pela tonelada reduzida nos projetos de mitigação, nos países em desenvolvimento.

O presente estudo propôs como objetivo geral avaliar a viabilidade do uso de biodigestores em granjas de suínos, visando à redução da poluição hídrica, bem como de gases do efeito estufa, como o gás $\mathrm{CH}_{4}$, gerando a possibilidade da negociação dos Créditos de Carbono adquiridos com a transformação de $\mathrm{CH}_{4}$ em $\mathrm{CO}_{2}$.

Este estudo tem como objetivos específicos descrever as formas de aproveitamento do gás $\mathrm{CH}_{4}$, como para geração de energia, verificar a forma de inserção do projeto no mercado de carbono, determinar um modelo de biodigestor para finalidade proposta e determinar o dimensionamento de uma granja para implantação.

\section{Materiais e métodos}

No estudo da viabilidade do uso de biodigestores para finalidade proposta, são considerados os custos de implantação e manutenção de uma unidade biodigestora, o custo de um sistema gerador de energia por meio de combustão do biogás e o custo de certificação do projeto. Adicionalmente, são contabilizados os benefícios financeiros que essa unidade biodigestora proporciona à propriedade, como negociação dos créditos de carbono e economia com energia.

Para descrever as formas de aproveitamento do gás $\mathrm{CH}_{4}$ foi feito um levantamento em bibliografia sobre dados da quantidade de energia produzida $(\mathrm{KWH}) \times$ volume de gás $\mathrm{CH}_{4}$ queimado, bem como de modelos geradores de ener- gia elétrica mediante a combustão de biogás.

Para se verificar a forma de inserção do projeto no Mercado de Carbono, fez-se uso das normas publicadas pelo Ministério de Ciência e Tecnologia, que é o gestor do Mecanismo de Desenvolvimento Limpo no Brasil.

Na comparação dos diferentes tipos de biodigestores para atividade proposta, usou-se literatura específica e consultas a sites, bem como, visitas a propriedades onde se faz uso de biodigestores para a finalidade proposta. Na determinação do modelo escolhido, foi levado em consideração pareceres técnicos e opinião de técnicos, como Sr. Eduardo Ken Kumagai, da Empresa Sansuy; Sr. Alexandre Akira, do Instituto de Tecnologia do Paraná - TECPAR; Sr. Nivaldo Wuaden, da Granja Wuaden e Sr. Airton Kunz, pesquisador da Embrapa Suínos e Aves.

Para determinar o destino dos resíduos provenientes da decomposição anaeróbica, foi feito levantamento em bibliografia.

$\mathrm{Na}$ execução dos cálculos, foi utilizada como referência uma unidade de produção com 300 unidades animais em ciclo completo.

Para execução do cálculo do tamanho do biodigestor, levou-se em consideração o volume de dejeto total (fezes, urina e água de limpeza) para cada unidade animal, multiplicado pelo total de animais, multiplicado pelo tempo de retenção hidráulica (30 dias), sendo 100 litros/dia a média geral de dejetos em todas as fases do ciclo de vida para cada unidade animal (EMBRAPA, 2003). Assim, temos a seguinte equação:

\section{Equação 1: Dimensionamento da capacidade do biodigestor.}

$$
V B m^{3}=\frac{V D T \cdot Q T A_{u n} \cdot T R H}{1000}
$$

Onde: $\mathrm{VBm}^{3}$ : volume do biodigestor em metros cúbicos

VDT: volume de dejeto total

QTA un $_{\text {: }}$ quantidade total de animais

TRH: tempo de retenção hidráulica 
Para executar o cálculo da quantidade de toneladas métricas de Biogás/ano provenientes da decomposição anaeróbica do esterco, levou-se em consideração o volume de esterco que cada unidade animal gera por dia $(2,35 \mathrm{~kg} / \mathrm{dia})$, o volume de biogás que esse dejeto gera por dia $\left(0,20 \mathrm{~m}^{3}\right)$ e a massa específica do biogás $\left(1,16 \mathrm{~kg} / \mathrm{m}^{3}\right)$ (BARRERA, 1993). Assim, temos a seguinte equação:

\section{Equação 2: Cálculo de toneladas de biogás por ano.}

Ton.biogás $s_{\text {ano }}=\frac{Q T A_{\text {un }} \cdot T_{\text {dias }} \cdot B G M_{\text {dia }} \cdot \text { M.esp. Biogás }}{1000}$

Onde: $Q T A_{u n}: \quad$ quantidade total de animais

$T_{\text {dias: }}: \quad$ tempo em dias

$B G M_{\text {dia }}$ : biogás gerado por matriz por dia

M.esp biogās: massa específica do biogás

Para se executar o cálculo da quantidade de metano produzida por ano em toneladas, devese utilizar o total de Biogás produzido por ano (EQUAÇÃO 3) e o valor correspondente à percentagem de metano existente no Biogás (60\%). Assim, temos a seguinte equação:

\section{Equação 3: Cálculo de toneladas de metano $\left(\mathrm{CH}_{4}\right)$ por ano.}

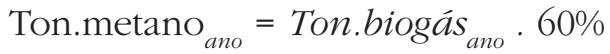

Para se executar o cálculo da quantidade de óxido nitroso produzido por ano, em toneladas, deve-se utilizar o total de Biogás produzido por ano (EQUAÇÃO 2) e o valor correspondente à percentagem de oxido nitroso existente no Biogás (14\%). Assim, temos a seguinte equação:

\section{Equação 4: Cálculo de toneladas de óxido nitroso $\left(\mathrm{N}_{2} \mathrm{O}\right)$ por ano.}

Ton.óxido.nitroso = Ton.biogás ${ }_{\text {ano }} .14 \%$

Para se executar o cálculo da quantidade de toneladas métricas reduzidas de dióxido de carbono por ano no projeto deve-se considerar o total em toneladas de metano por ano (EQUAÇÃO 3), o total em toneladas de óxido nitroso por ano
(EQUAÇÃO 4) e o GWP do $\mathrm{CH}_{4}$ e $\mathrm{N}_{2} \mathrm{O}$, respectivamente, 21 e 310 (BRASIL, 2006). Para coeficientes de cálculo foram usados GWP 20 para $\mathrm{CH}_{4}$ e GWP 309 para $\mathrm{N}_{2} \mathrm{O}$, pois ambos depois de reduzidos têm seu GWP mantido com coeficiente 1. Assim temos a seguinte equação:

Equação 5: Cálculo de toneladas métricas de dióxido de carbono $\left(\mathrm{CO}_{2}\right)$ reduzidas por ano no projeto.

Ton.métrica. $\mathrm{CO}_{2} /$ ano $=$ Ton.metano ${ }_{\text {ano }}+$ Ton.óxido.nitroso ${ }_{\text {ano }}$

Para calcular o volume total de biogás produzido por ano, deve-se considerar o total de matrizes na unidade de produção, neste caso, 300 matrizes. Cada matriz gera, em média, 2,35 kg de esterco por dia. O volume de biogás que esse esterco produz que é de $0,20 \mathrm{~m}^{3}$ e o volume de $\mathrm{CH}_{4}$ presente no biogás é 60\% (BARRERA, 1993). Assim, temos a seguinte equação:

\section{Equação 6: Cálculo do volume total de $\mathrm{CH}_{4}$ gerado} por ano.

V.totalCH $m_{3} /$ ano $=\mathrm{QTA}_{\mathrm{un}} \cdot B G M_{d i a} \cdot T_{d i a} \cdot P \cdot C H_{4}$

Onde: $Q T A_{\text {un }}$ : quantidade total de animais

$B G M_{\text {dia }}$ : quantidade de esterco dia

$T_{\text {dias: }}: \quad$ tempo em dias

P.CH: percentagem de $\mathrm{CH}_{4}$

Para calcular o volume total de energia gerada por ano, deve-se considerar o total de produção de $\mathrm{CH}_{4}$ e o dado de geração de $\mathrm{KW}$ por metro cúbico queimado $\left(0,714 \mathrm{KW} / \mathrm{m}^{3} / \mathrm{CH}_{4}\right)$ multiplicado pela eficiência do sistema (80\%) (BARRERA, 1993). Assim, temos a seguinte equação:

Equação 7: Cálculo da energia elétrica total gerada por ano com a queima do $\mathrm{CH}_{4}$

E.total. $K W_{\text {ano }}=$ V.total. $\mathrm{CH}_{4} \mathrm{~m}^{3} /$ ano $. \mathrm{KW} /$ $m^{3} \mathrm{CH}_{4}$ queimado. EF

Onde: E.total $\mathrm{CH}_{4 m \text { /ano: }}^{3}$ : volume total de $\mathrm{CH}_{4}$ gerado por ano

$\mathrm{KW} / \mathrm{m}^{3} \mathrm{CH}_{\text {4queimado }}: \quad \mathrm{KW}$ gerado por metro cúbico de $\mathrm{CH}_{4}$ queimado $E F$ : eficiência 


\section{Resultados}

Pelo estudo em questão, pode-se afirmar que existem basicamente duas formas de aproveitamento do gás $\mathrm{CH}_{4}$, geração de energia térmica e elétrica. Nas duas situações, o biogás necessita ser queimado para ser transformado em energia. Para seu aproveitamento na forma de energia térmica, observou-se diferentes formas de uso, como, por exemplo: a queima do biogás em uma caldeira, em que o ar aquecido se desloca por tubulações de ferro galvanizado dentro de um aviário e o aquece. Outra forma de uso do biogás para aquecimento de aviário é por campânulas, que ficam distribuídas dentro da unidade. Nessas, o biogás é canalizado e queimado, quando necessário por meio de chama piloto. Essas campânulas vêm sendo avaliadas na propriedade do Sr. Nivaldo Wuaden, em Piritiba, Santa Catarina, sob responsabilidade da Empresa GSI, a qual vem desenvolvendo esse sistema para uso com biogás. Pode-se afirmar que ambas as utilizações mencionadas acima são funcionais.

Outro exemplo do uso do metano proveniente de biodigestores é o da Cooperativa Central Aurora, em Concórdia, Santa Catarina, que vem utilizando o biogás resultante do dejeto suíno de suas granjas para a flambagem das quatro mil carcaças de suínos abatidos por dia (CATARINENSE, 2006).

Outro projeto que está em funcionamento é o da granja Lanznaster, em Chapecó, Santa Catarina. Os biodigestores foram montados em sistema de parceria com a empresa certificadora AgCert, que construiu quatro biodigestores na propriedade de Sr. Mário Lanznaster em troca dos créditos resultantes da queima do metano liberado pelos dejetos, repassando $10 \%$ da venda para o produtor. Esse contrato tem duração de 10 anos.

Neste projeto, o produtor com recursos financeiros próprios investiu $\mathrm{R} \$ 40.000,00$ em um sistema gerador para, em vez de apenas queimar o gás, transformá-lo em energia elétrica. O gás queimado num motor gerador consome $27 \mathrm{~m}^{3}$ de gás por hora e gera 60 quilowatts $(\mathrm{kW})$ de energia. De acordo com o gerente da granja, Sr. Fabiano Lanznaster, a energia gerada é utilizada para movimentar 15 motores, utilizados em máquinas na fabricação de ração. A economia mensal atinge $\mathrm{R} \$$ 1.800,00 (CATARINENSE, 2006).
Outras formas de aproveitamento do biogás podem ser citadas, como: sua queima em caldeiras para aquecimento de água e queima para flambagem de carcaças de suínos (projeto Cooperativa Aurora). Considerando que são sistemas simples de funcionamento, pode-se afirmar que são viáveis, do aspecto funcional do sistema.

$\mathrm{Na}$ forma de aproveitamento para geração de energia elétrica, deve-se fazer o uso de geradores movidos a biogás. Existem no Brasil modelos desenvolvidos para essa finalidade, como da Empresa TRIGÁS. Esses geradores variam sua capacidade de geração de energia de acordo com a sua potência, tendo em vista que o gerador consome determinado volume de biogás em $\mathrm{m}^{3}$ por hora, deverá adequar a sua potência de acordo com a capacidade de produção de biogás da propriedade por dia.

Nas situações descritas sobre aproveitamento do biogás, faz-se necessário o uso de um sistema compressor e de um sistema de filtragem e secagem do biogás, pois esse contém umidade e gases indesejáveis, como o gás sulfídrico, grande responsável pela ineficiência do funcionamento a longo prazo em sistemas que não utilizam filtros, pois esse é convertido a ácido sulfúrico, o que leva à oxidação precoce dos componentes dos equipamentos, sejam eles geradores, queimadores ou campânulas.

Como sistemas de filtragem para reduzir a umidade são utilizados filtros, com elementos filtrantes feitos em espuma de diferentes densidades e drenos para retirada de acúmulos internos. Esses filtros são instalados após o sistema de compressão. Para remoção do gás sulfídrico, podem ser usados filtros de esponja de ferro, que reterão o gás sulfídrico, pois esse tem alta afinidade por óxido de ferro. Esse sistema de filtragem deve ser instalado antes do sistema de compressão, uma vez que contém componentes mecânicos sensíveis ao gás sulfídrico.

O Instituto Sadia de Sustentabilidade faz uso de biodigestores, cuja meta é instalar 1000 biodigestores no ano de 2006 e chegar aos 3,5 mil integrados de suínos ao final de 2007. O Instituto deve investir R\$ 60 milhões, que serão compensados pelo produtor com a geração dos Créditos de Carbono. A estimativa é que os pequenos criadores possam quitar o investimento em cinco anos (informação fornecida por: Sr. Julio Cesar Cavasin - Diretor técnico do Instituto Sadia de Sustentabilidade). 
Para inserção de um projeto no "Mercado de Carbono", é necessário que antes ocorra a emissão dos Certificados de Redução de Emissão. Dessa maneira, é necessário que o projeto adote uma série de procedimentos, como detalhado a seguir.

A primeira etapa a ser cumprida pelos participantes, após a elaboração de sua proposta, é selecionar e contratar uma Instituição credenciada para validar o seu projeto. A instituição operacional deverá rever toda a documentação do projeto que foi apresentada, avaliá-la e confirmar que todos os requisitos de participação preestabelecidos foram atendidos (CEBDS, 2006).

Durante a etapa de validação, se a entidade operacional designada constatar que uma nova metodologia foi utilizada para determinar a linha de base do projeto ou para monitoração, essa metodologia, a documentação do projeto e a identificação dos participantes deverão ser encaminhadas ao Conselho Executivo da ONU para avaliação. Caso a metodologia seja aprovada, ela passará a ser adotada como padrão para avaliação de projetos similares, a serem analisados posteriormente e, assim, ao ser divulgada pelo Conselho Executivo da ONU, se tornará de domínio público. Somente após a aprovação da metodologia é que a etapa de validação poderá prosseguir. Caso o Conselho Executivo exija a revisão, os participantes do projeto deverão revisar a metodologia de forma apropriada, considerando as orientações fornecidas. A Entidade Operacional Designada deverá, ainda, informar aos participantes sobre a validação ou não do projeto, sendo que, em caso de recusa, deverão apontar as não-conformidades encontradas e/ou os motivos que conduziram à decisão. Ao final do processo, o relatório de validação deverá se tornar público (CEBDS, 2006).

Quando a atividade de projeto for considerada válida, a Entidade Operacional Desig- nada deverá solicitar o registro ao Conselho Executivo, mediante a entrega de um relatório de validação e da documentação de projeto recebida.

O registro deverá ser fornecido pelo Conselho Executivo em oito semanas, a menos que uma das partes envolvidas no projeto ou, no mínimo, três membros do Conselho Executivo requeiram uma revisão, por questões associadas aos requisitos de validação (CEBDS, 2006).

Uma proposta de projeto recusada poderá ser reapresentada para validação e subseqüente registro após a incorporação das revisões pertinentes (CEBDS, 2006).

Conforme comentado no item anterior, a emissão dos CERs pelo Conselho Executivo somente será feita após verificação e certificação do projeto e de suas respectivas emissões reduzidas. As etapas de verificação e de certificação também deverão ser executadas por instituições credenciadas pelo Conselho Executivo (CEBDS, 2006).

A verificação é um processo periódico, de revisão independente, para determinação exposta da efetiva redução das emissões de gases de efeito estufa ocorrida nos projetos de Mecanismo de Desenvolvimento Limpo, durante o período de verificação. A certificação é uma garantia por escrito, fornecida pela Entidade Operacional Designada, que assegura que foram constatadas reduções de Gases de Efeito Estufa para a atividade de projeto, durante o período de tempo especificado (CEBDS, 2006).

Para a obtenção dos CERs, os participantes devem selecionar e contratar uma instituição credenciada para verificar e certificar o seu projeto. Essa instituição deverá efetuar um relatório de monitoramento e torná-lo publicamente disponível (CEBDS, 2006).

A Figura 1 apresenta de forma sintética o ciclo de um projeto de Mecanismo de Desenvolvimento Limpo, visando facilitar o entendimento das várias fases do processo. 


\section{FIGURA 1 - Ciclo de um projeto de mecanismo de desenvolvimento limpo.}

Figure 1 - Flowchart of a clean development mechanism project.

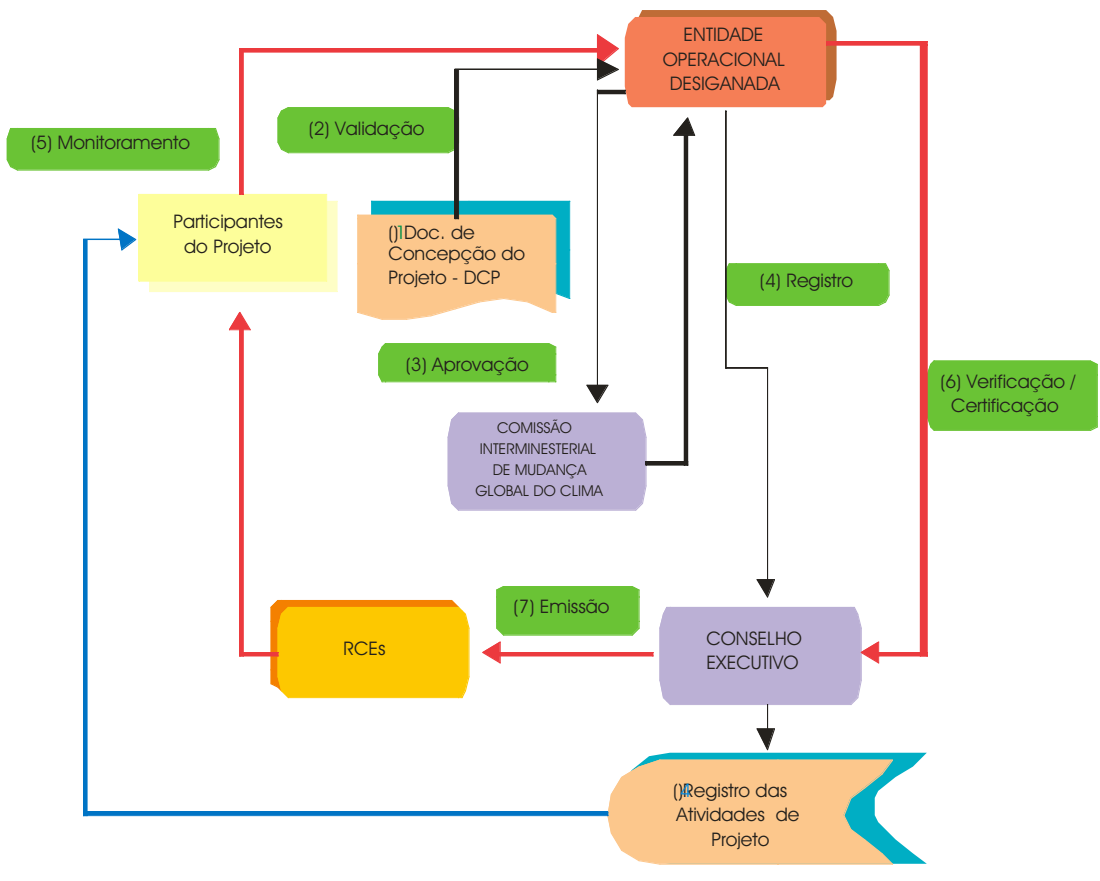

Após a emissão dos Certificados de Emissão de Redução do projeto, esse pode ser anexado, via internet, sem ônus algum, na Bolsa de Mercadorias e Futuro do Rio de Janeiro BM\&F, ficando seu projeto visível a qualquer interessado. Esses CERs podem também ser negociados por meio de outras Bolsas de Valores, como Chicago Climate Exchange (CCX), chamada de bolsa voluntária de Chicago ou European Climate Exchange (ECX), Bolsa da Comunidade, para assuntos ligados ao Mercado de Carbono.

Existem outros mecanismos para se efetuar a negociação dos Certificados de Emissão de Redução, como venda direta a empresas interessadas, ou ainda, a criação do projeto em parceria com uma empresa interessada nos Créditos de Carbono.

Pelo estudo em questão, foram avaliados casos de projetos em andamento, como o do Instituto de Tecnologia do Paraná - TECPAR, que faz uso de uma Unidade Piloto na cidade de Toledo, Paraná, para poder avaliar os aspectos técnicos de funcionamento do sistema biodigestor.

Existem diversos modelos de biodigestores descritos em literatura, como modelo indiano, da marinha, chinês. Porém, são biodigestores que foram criados com a finalidade de aten- der pequenas propriedades e não propunham o mesmo uso ao qual se necessitava para atividade proposta, assim sendo, não serão realizadas comparações entre diferentes modelos, de forma que para nossa necessidade existe um modelo mais apropriado, que varia apenas em tamanho.

O modelo determinado para simulação foi o mesmo que vem sendo utilizado por várias unidades produtoras em todo o território nacional. Esse biodigestor é fabricado pela Empresa Sansuy e tem como diferencial o fato de ser um sistema lacrado e de custo mais barato, tanto para aquisição quanto para manutenção. Esse modelo é denominado Minibio Lacrado, tem sua câmera de digestão (parte inferior) unida ao gasômetro (parte superior) e não requer construção da câmera de digestão em alvenaria, sendo necessário somente fazer a escavação da área onde o biodigestor ficará instalado.

O modelo mencionado foi utilizado para simulação dos cálculos referentes a custos de instalação do biodigestor, capacidade de processamento do dejeto e geração de energia. Para geração de energia elétrica utilizou-se o gerador da empresa TRIGÁS. As tabelas a seguir descrevem os custos e as receitas do projeto. 
TABELA 1 - Custo de instalação de sistema biodigestor, para uma unidade com 300 matrizes em ciclo completo.

Table 1 - Installation cost of a bio-digester system, for a 300 matrices unit, in complete cycle.

\section{Descrição}

Seis minibios $8 \times 16 \times 2 \mathrm{~m}$

Uma lagoa $15 \times 18 \times 2,5 \mathrm{~m}$

Kit gás mais instalação

Terraplanagem e escavação

Total

\section{Valor em R\$}

$45.966,00$

$6.123,60$

$6.000,00$

$3.000,00$

Nota: Dados fornecidos pela empresa Sansuy, divisão de produtos especiais em junho 2006.

* Dados cotados pelo autor.

TABELA 2 - Custo de instalação de sistema para geração de energia.

Table 2 - Installation cost of an energy generation system.

\begin{tabular}{ll}
\hline Descrição & Valor em R\$ \\
\hline Grupo gerador trigas & $27.000,00$ \\
\hline
\end{tabular}

Nota: Dados fornecidos pela empresa TRIGÁS, em junho de 2006.

TABELA 3 - Custo de aprovação de um projeto de Mecanismo de Desenvolvimento Limpo.

Table 3 - Approval cost of a Clean Development Mechanism project.

\begin{tabular}{ll}
\hline Descrição & Valor em R\$̣ \\
\hline Validação & $29.100,00$ \\
ONU & $14.550,00$ \\
Verificação & $14.550,00$ \\
\hline Total & $\mathbf{5 8 . 2 0 0 , 0 0}$ \\
\hline
\end{tabular}

Nota: Dados fornecidos pelo Instituto de Tecnologia do Paraná - TECPAR, em junho de 2006.

TABELA 4 - Retorno do capital investido com a negociação dos CERs sem geração de energia até o ano de 2012.

Table 4 - Return of the capital invested with the negotiation of the CERs without energy generation until the year 2012.

\begin{tabular}{ll}
\hline Descrição & Valor em R\$ \\
\hline Biodigestor (despesa) & $61.089,60$ \\
Manutenção do projeto e do biodigestor período de & \\
cinco anos (despesa) & $7.500,00$ \\
Aprovação do projeto (despesa) & $58.200,00$ \\
Negociação dos CERs pelo período de seis anos & $203.007,00$ \\
Retorno total em seis anos & $76.217,00$ \\
\hline
\end{tabular}

Nota: Cálculos do autor. 
TABELA 5 - Retorno do capital investido com a negociação dos CERs e geração de energia até o ano de 2012.

Table 5 - Return of the capital invested with the negotiation of the CERs and generation of energy until the year 2012.

\begin{tabular}{lc}
\hline Descrição & Valor em R\$̣ \\
\hline Biodigestor (despesa) & $61.089,60$ \\
Manutenção do projeto, do biodigestor e gerador período de & \\
cinco anos (despesa) & $12.500,00$ \\
Aprovação do projeto (despesa) & $58.200,00$ \\
Grupo gerador (despesa) & $27.000,00$ \\
Negociação dos CERs pelo período de seis anos & $195.297,60$ \\
Economia com energia elétrica pelo período de seis anos & $8.331,17$ \\
Retorno total em seis anos & $44.839,17$ \\
\hline
\end{tabular}

Nota: Cálculos do autor.

Os cálculos foram feitos até o ano de 2012, devido ao fato de que a partir desta data não se sabe ao certo o que ocorrerá com este mercado, tendo em vista que esse é o prazo para os países do Anexo I cumprirem suas metas de redução.

Adicionalmente, além da produção de energia e comercialização de Créditos de Carbono, é também possível aproveitar os resíduos pro- venientes da biodigestão anaeróbica, pode se fazer seu uso como fertilizante agrícola. Na tabela 6 está apresentada a comparação entre o dejeto fresco e biodigerido, em que se verifica um aumento percentual dos nutrientes, principalmente do fósforo e potássio. Isso ocorre em função da redução no teor de carbono, devido à formação de $\mathrm{CH}_{4} \mathrm{e}$ $\mathrm{CO}_{2}$.

TABELA 6 - Comparação entre o dejeto fresco e biodigerido.

Table 6 - Comparison between the cool and bio-digested dejection.

\begin{tabular}{lcc}
\hline Especificação & $\begin{array}{l}\text { Esterco fresco } \\
\text { dados em \% }\end{array}$ & $\begin{array}{l}\text { Esterco biodigerido } \\
\text { dados em \% }\end{array}$ \\
\hline Umidade & 81,80 & 80,50 \\
Nitrogênio orgânico & 0,34 & 0,60 \\
Nitrogênio amoniacal & - & 0,15 \\
$\mathrm{P}_{2} \mathrm{O}_{5}$ total & 0,13 & 0,35 \\
$\mathrm{~K}_{2} \mathrm{O}$ total & 0,40 & 0,70 \\
Matéria orgânica & 16,40 & 15,80 \\
\hline
\end{tabular}

Fonte: NOGUEIRA, 1993. 


\section{Conclusões}

Como formas de aproveitamento do biogás, foi possível verificar que a sua utilização, seja para geração de energia térmica ou elétrica, é viável, tanto no aspecto técnico quanto financeiro, pois existem equipamentos desenvolvidos para serem utilizados com esta fonte energética e os custos com a aquisição e manutenção é compensado a curto prazo, como observado no estudo, onde se tem o retorno do capital investido em três anos. Assim, pode-se afirmar que o uso do biogás como uma alternativa de matriz energética é viável econômica e ambientalmente.

Foi possível verificar que a validação de um projeto de Mecanismo de Desenvolvimento Limpo consiste em uma série de tramitações que tornam o processo complexo e oneroso, porém toda a tecnologia e conhecimento que se faça necessária para elaboração e conclusão de um projeto estão disponíveis no Brasil, principalmente no Ministério de Ciência e Tecnologia.

O modelo "Minibio" vem se mostrando a tecnologia mais viável, tanto no aspecto técnico quanto financeiro, sendo que atualmente os esforços vêm se direcionando não para criação de novos modelos e sim para o aperfeiçoamento desses, como, por exemplo: o aquecimento na entrada do dejeto, o que é viável em regiões mais frias, como no Sul do Brasil, principalmente no inverno, diminuindo a troca de calor. Isso facilita a manutenção de elevada atividade microbiológica dentro do biodigestor, o que faz com que o volume de produção de gás $\mathrm{CH}_{4}$ se mantenha constante.

A unidade com 300 matrizes se mostrou viável, cobrindo os custos de investimentos, e deixando uma margem razoável de renda. Considerando possíveis quedas na produção de gás $\mathrm{CH}_{4}$, bem como a variação no valor pago pela tonelada métrica de $\mathrm{CO}_{2}$, pode se afirmar que 300 matrizes em ciclo completo é um número mínimo para que o projeto garanta retorno. Assim, granjas que trabalhem com números inferiores a esse e se proponham a executar projeto semelhante podem não ter o retorno do capital investido.

Considera-se que a utilização da tecnologia é viável, porém deve ser feito um estudo de viabilidade técnica e econômica, em função das características da granja, localização e do Mercado de Carbono, para que esse aponte a viabilidade ou não da execução para a situação local.

\section{Referências}

BARRERA, P. Biodigestores. São Paulo, SP: Cone, 1993.

BRASIL. Ministério da Ciência e Tecnologia Projeto de Mitigação SMDA GEE BR05-B-15, Paraná, Santa Catarina e Rio Grande do Sul, Brasil. Disponível em: <http:// www.mct.gov.br/ clima>. Acesso em: 05 maio 2006.

CATARINENSE, D. Dejeto suíno gera energia e Créditos de Carbono. Disponível em: < http:// www.carbonobrasil.com>. Acesso em: 02 maio. 2006.

CEBDS. Roteiro básico para elaboração de um projeto de mecanismo de desenvolvimento limpo - mdl. Disponível em: <http:// www.cebds.com>. Acesso em: 08 maio. 2006.

EMBRAPA, 2003. Biodigestor e Utilização de Biogás. Santa Catarina: Embrapa, 2003.

KHALILI, A. E. O que são créditos de carbono? www.ambientebrasil.com.br/noticias/ index.php3\&conteudo=./noticias/amyra/ creditos.html>. Acesso em: 07 jul. 2005.

LOMBARDI, A. Créditos de carbono movimentaram US\$ 4 bilhões em 2005. Disponível em: $<$ http://www.clima.org.br>. Acesso em: 04 mar. 2006.

NOGUEIRA, L. Biodigestão a alternativa energética. São Paulo, SP: Nobel, 1986.

ROCHA, 2003. Aquecimento global e o Mercado de carbono: Uma aplicação do modelo cert. Disponível em: <http://www.teses.usp.br/teses $>$. Acesso em: 11 fev. 2006.

Recebido: 12/08/2005

Aprovado: 20/12/2005 